\title{
Intestinal Behçet and Crohn's disease: two sides of the same coin
}

\author{
Simona Valenti, Romina Gallizzi, Dominique De Vivo and Claudio Romano*
}

\begin{abstract}
Behçet's disease (BD) and Crohn's disease (CD) are chronic immune-mediated, inflammatory disorders affecting many different systems (joints, skin, eyes, gastrointestinal and biliary tracts). Both disorders have fluctuating courses and when gastrointestinal symptoms are prevalent, differential diagnosis can be difficult. BD involves the gastrointestinal tract in $10-15 \%$ of cases with localized lesions in the ileocecal region. The clinical picture is heterogeneous with various clusters of disease expression. CD is a chronic inflammatory disorder, which can affect any part of the intestinal tract, as well as extra-intestinal tissue. Factors that contribute towards the pathogenesis of both disease include the host's genetic profile, and immune system, and environmental factors such as the gut microbiota. The aim of this manuscript is to provide a narrative review of clinical features of BD and CD, highlighting the importance of differential diagnosis and therapeutic approach, especially in the presence of gastrointestinal involvement. A comprehensive search of published literature using the Pubmed (http://www. ncbi.nlm.nih.gov/pubmed/) database was carried out to identify all articles published in English from 1999 to October 2016, using 4 key terms: "Behçet Disease", "Intestinal Behçet's Disease", "Crohn's Disease" and" Inflammatory Bowel Disease".
\end{abstract}

Keywords: Behçet disease, Crohn's disease, Inflammatory bowel diseases, Intestinal Behçet disease

\section{Background}

Behçet's disease (BD) was first described by the Turkish dermatologist Hulusi Behçet in 1937 as a syndrome with oral and genital ulcerations and ocular inflammation $[1,2]$. It is a rare multi-systemic inflammatory disease with unknown etiology and a chronic recurrent pattern, characterized by recurrent oral and genital aphthous/ulcers with muco-cutaneous, ocular, articular, vascular, and/or gastrointestinal lesions. BD is included both in vasculitis, affecting vessels of all kinds and sizes, and auto-inflammatory disease classifications [3]. Crohn's disease (CD) is a type of inflammatory bowel disease that may affect any part of the gastrointestinal tract from mouth to anus. It often includes both intestinal (abdominal pain, diarrhoea, vomiting) and extra-intestinal symptoms (fever, weight loss, anaemia, skin rashes, arthritis, inflammation of the eye) [4]. When the gastrointestinal

\footnotetext{
* Correspondence: romanoc@unime.it

Unit of Pediatrics, Department of Human Pathology in Adulthood and

Childhood "G. Barresi", University of Messina, Viale Consolare Valeria, 98124 Messina, Italy

(c) The Author(s). 2017 Open Access This article is distributed under the terms of the Creative Commons Attribution 4.0 International License (http://creativecommons.org/licenses/by/4.0/), which permits unrestricted use, distribution, and reproduction in any medium, provided you give appropriate credit to the original author(s) and the source, provide a link to the Creative Commons license, and indicate if changes were made. The Creative Commons Public Domain Dedication waiver (http://creativecommons.org/publicdomain/zero/1.0/) applies to the data made available in this article, unless otherwise stated. tract is involved, a differential diagnosis between $\mathrm{BD}$ and $C D$ is very difficult. There are no pathognomonic laboratory tests or endoscopic findings of intestinal $\mathrm{BD}$, although few, large and deep ulcerations with discrete borders are described as a characteristic endoscopic pattern. Recently, novel diagnostic criteria and a disease activity index have been proposed in the diagnosis of intestinal BD [5]. Treatment for intestinal $\mathrm{BD}$ is similar to $\mathrm{CD}$, such as steroids, immunomodulators and biologic agents (anti-tumour necrosis factor $\alpha$ antibody) [6]. The goal of this review is to describe these clinical conditions with similarities and differences from clinical, therapeutic and surgical points of view.

\section{Epidemiology}

BD has the highest incidence in countries located along the ancient Silk Road, stretching from Asia to the Mediterranean countries. It is therefore very common in Turkey (80-370 cases per 100,000 inhabitants), followed by Asia and Middle Eastern countries, including Israel, Saudi Arabia and Iran [7]. Prevalence in the USA and 
Europe ranges from 0.12 to 7.5 patients per 100,000 inhabitants [8]. Age at onset of BD is usually in young adulthood (25-30 years), but also occasionally in children before the age of 16 years, in 4 to $26 \%$ of cases. Intestinal $\mathrm{BD}$ occurs in 3-60\% of $\mathrm{BD}$ patients, with higher frequency of gastrointestinal involvement in East Asian countries such as Korea and Japan than in Western or Middle Eastern countries [1, 9]. Gastrointestinal involvement is higher in patients with childhood-onset [10]. The annual incidence of $C D$ varies from 0 to 20.2 per 100,000 in North America and $0.3-12.7$ per 100,000 in Europe [11]. It is highest in Western countries in young individuals aged 15 to 29 years $[7,12]$.

\section{Pathogenesis}

Intestinal BD shares many characteristics with inflammatory bowel disease (IBD), including genetic background, clinical manifestations, and therapeutic strategies. Although etiology is unknown, BD may represent aberrant immune activity triggered by exposure to specific infectious or environmental agents in patients with an underlying genetic predisposition [13]. Human leukocyte antigen (HLA)-B51 is considered the most important genetic factor of $\mathrm{BD}$ associated with increased disease severity $[14,15]$. The major susceptibility gene for $C D$ is nucleotide oligomerization domain 2/caspase-activation recruitment domain containing protein 15 (NOD2/ CARD15) [16]. Caspase recruitment domain-containing protein 9 (CARD9) is a scaffold protein encoded by the CARD9 gene which is located on chromosome 9q34.3. CARD9 belongs to the caspase-associated recruitment domain (CARD) protein family and plays important roles in host defence and immune homeostasis through assembling multifunctional signalling complexes [16]. Mizuki et al., in a genome-wide association study conducted in patients with $\mathrm{BD}$, reported an association for BD with interleukin (IL) 10 and the IL23R-IL12RB2 loci. They identified two suggestive associations on chromosomes 1p31.3 (IL23R-IL12RB2) and 1q32.1 (IL10) both of which predispose individuals to BD [17]. Similarly, IL10 or IL23R variants, although in different polymorphisms, were also observed in IBD patients, suggesting that $\mathrm{BD}$ and $\mathrm{CD}$ have similar pathogenesis and genetic backgrounds $[18,19]$. BD is associated with the intergenic region between IL23R and IL12RB2, while IBD presents an association with variants in IL23R, IL12B, and TYK2 [20]. Increased Th1, Th17, CD4+ and CD8 $+\mathrm{T}$ cell, and $\gamma \delta+\mathrm{T}$ cell activity was found in both the serum and/or inflamed tissues of $\mathrm{BD}$ and $\mathrm{CD}$ patients, which suggests that innate and adaptive immunity are involved in the pathogenesis of both diseases [18]. Environmental factors also contribute to triggering inflammation, both in $\mathrm{BD}$ and IBD, such as smoking, diet, infectious pathogens and antibiotics, medications, lifestyle (stress, sleep and exercise) [11].

\section{Clinical presentation and diagnosis}

The manifestations of $\mathrm{BD}$ are similar to those of IBD, specifically uveitis, arthritis, oral ulcers, pyoderma gangrenosum, vaso-occlusive disease, and thrombotic events [12]. Uveitis in BD can be characterized by chronic pan-uveitis or posterior uveitis with necrotizing retinal vasculitis and tends to be more recurrent and sight threatening than other endogenous uveitis. Other ocular manifestations also include iridocyclitis, keratitis, episcleritis, scleritis, vitritis and optic neuritis [21,22]. The most commonly reported ocular manifestations in IBD are dry eye, blepharitis, episcleritis, or anterior uveitis. When related to $C D$, uveitis is frequently bilateral, with insidious onset, and long-lasting, although characteristic acute anterior uveitis with sudden onset may occur [23]. Arthropathy is a common manifestation in $\mathrm{BD}$ : arthralgia, oligoarthritis and polyarthritis are the most common reported forms of joint involvement [24]. Arthropathies associated with IBD in the spondyloarthritis group can be divided into axial and peripheral involvement [23]. Genital lesions and neurologic involvement are more common in BD. Vascular complications are present in one third of $\mathrm{BD}$ patients. $\mathrm{BD}$ involves the gastrointestinal tract in 10-15\% of cases with localized lesions that occur in the ileocecal region. Gastrointestinal manifestations usually occur 4.5-6 years later than the onset of oral ulcerations. Sometimes, however, intestinal lesions can precede extra-intestinal manifestations [13]. Anal complications such as stricture, fistula, and abscess formation, which are frequently observed in a third of patients with $\mathrm{CD}$ due to its transmural mucosal involvement, are rare in $\mathrm{BD}$, occurring in less than $1 \%$ of patients $[15,25]$. CD is an inflammatory bowel disease that may affect any part of the gastrointestinal tract from mouth to anus, presenting at onset with a clinical picture characterized by a combination of symptoms/ signs such as abdominal pain, diarrhoea, rectal bleeding, nausea, vomiting, abdominal tenderness, weight loss and fever. It often includes, like BD, extra-intestinal signs and symptoms (fever, weight loss, anaemia, skin rashes, arthritis, inflammation of the eye) affecting different systems with skin, ocular, articular lesions [4]. Classically, CD has a clinical manifestation with pain, diarrhoea and weight loss [26]. Similar to adults, children with IBD may present with a range of symptoms, depending on the location, severity and chronicity of inflammation [27]. Children with $C D$, presenting less specific symptoms than those with ulcerative colitis [28], have a longer period of symptoms prior to diagnosis that contributes to various short- or long-term consequences, including impaired linear growth and delayed pubertal development and inappropriate therapies or interventions [29]. While 
diagnosis of CD is based on endoscopic and histological features, there is no specific diagnostic test for BD and diagnosis depends on clinical features. In 1990, the International Study Group (ISG) for BD defined the diagnostic criteria of $\mathrm{BD}$. It can be considered in the presence of recurrent oral ulcerations plus 2 of the following criteria: recurrent genital ulcerations, eye lesions, skin lesions, positive results from a pathergy test (Fig. 1) [30]. In 2014, new criteria for BD diagnosis called ICBD (International Criteria for Behcet's Disease) were proposed and include two additional clinical criteria, neurological and vascular involvement, permitting diagnosis even without the presence of oral aphthous lesions which were considered mandatory in previous ISG classifications [12]. An international expert consensus group (the pediatric $\mathrm{BD}$, PEDBD group) has recently proposed a new set of criteria for the classification of BD in children [31]. These diagnostic criteria for BD do not include intestinal symptoms. Cheon et al. defined novel diagnostic criteria for intestinal BD in Korean patients with ileum-colonic ulcers based on endoscopic features (typical or atypical intestinal BD ulcerations) and clinical patterns (systemic symptoms, oral ulcerations or extra-intestinal manifestations). The positive predictive value and accuracy of these criteria were 86.1 and $91.1 \%$ respectively [5] (Fig. 2). Previously, some clinicians had used Crohn's disease activity index (CDAI) for evaluating intestinal BD activity. CDAI is the most common indicator used in $\mathrm{CD}$ relapses and includes some criteria such as: present state of being, abdominal pain, number of bowel movements, haematocrit value, body weight, and administered drugs [32]. The Korean IBD
Study Group has developed a disease activity index for intestinal Behçet's disease (DAIBD) [33]. DAIBD includes clinical features that have been present over the preceding 7 days such as the general condition of patient, extraintestinal manifestations, intestinal complications, abdominal symptoms and signs, fever and stool frequency not requiring laboratory data or endoscopic findings (Fig. 3). Each item has a single score and total score can differentiate disease activity into "severe," "moderate," "mild," and "quiescent", showing much higher responsiveness than the CDAI ( $r=0.812$ vs. $r=0.645$, respectively) but no significant association with endoscopic activity [34]. There are no pathognomonic laboratory tests for $\mathrm{BD}$ diagnosis. In the presence of active $\mathrm{BD}$, such as in patients with IBD or other forms or vasculitis, levels of serum markers of inflammation, C-reactive protein and erythrocyte sedimentation rate, are elevated. Anti-Saccharomyces cerevisiae antibodies (ASCA) are anti-glycan antibodies directed against the phosphopeptido mannans found in the cell wall of baker's and brewer's yeast (Saccharomyces cerevisiae). Choi et al. have demonstrated that ASCA positivity is possible in up to $44 \%$ of patients with intestinal BD and is associated with an increased surgical risk [35]. Anti $\alpha$ enolase antibodies (AAEA) have been observed in patients with BD. The $\alpha$-enolase protein is a glycolytic enzyme that serves as a plasminogen receptor on the surface of a variety of hematopoietic, epithelial, and endothelial cells and is crucial in intravascular and pericellular fibrinolytic systems [36]. Evidence suggests that $\alpha$-enolase plays an important role in autoimmune and inflammatory diseases. Recently, Lee et al. reported that $\alpha$-enolase is the target

\begin{tabular}{|c|c|}
\hline CRITERIA & DESCRIPTIONS \\
\hline Recurrent oral ulcerations & $\begin{array}{l}\text { Minor or major aphthous ulcerations or herpetiform } \\
\text { ulcerations observed by a physician or patient at least } 3 \\
\text { times in a } 12 \text {-month period }\end{array}$ \\
\hline \multicolumn{2}{|c|}{ Plus 2 of the following criteria in the absence of other clinical explanations: } \\
\hline Recurrent genital ulcerations & $\begin{array}{l}\text { Aphthous ulcerations or scarring observed by a physician } \\
\text { or patient }\end{array}$ \\
\hline Eye lesions & $\begin{array}{l}\text { Anterior or posterior uveitis or vitreous cells seen on slit- } \\
\text { lamp examination; } \\
\text { Retinal vasculitis observed by an ophthalmologist }\end{array}$ \\
\hline Skin lesions & $\begin{array}{l}\text { Erythema nodosum observed by a physician or patient: } \\
\text { pseudofolliculitis papulopustular lesions; acneiform } \\
\text { nodules observed by a physician in post adolescent } \\
\text { patients who are not taking corticosteroids }\end{array}$ \\
\hline Positive results from pathergy test & $\begin{array}{l}\text { Oblique insertion of a } 20-22 \text {-gauge needle } 5 \mathrm{~mm} \text { into the } \\
\text { skin, causing a papule } 2 \mathrm{~mm} \text { or larger. The test is } \\
\text { generally performed on the forearm and a physician reads } \\
\text { results after } 24-48 \text { hours. }\end{array}$ \\
\hline
\end{tabular}

Fig. 1 International Study Group Diagnostic Criteria for Behçet's Disease. Adapted from [30] 


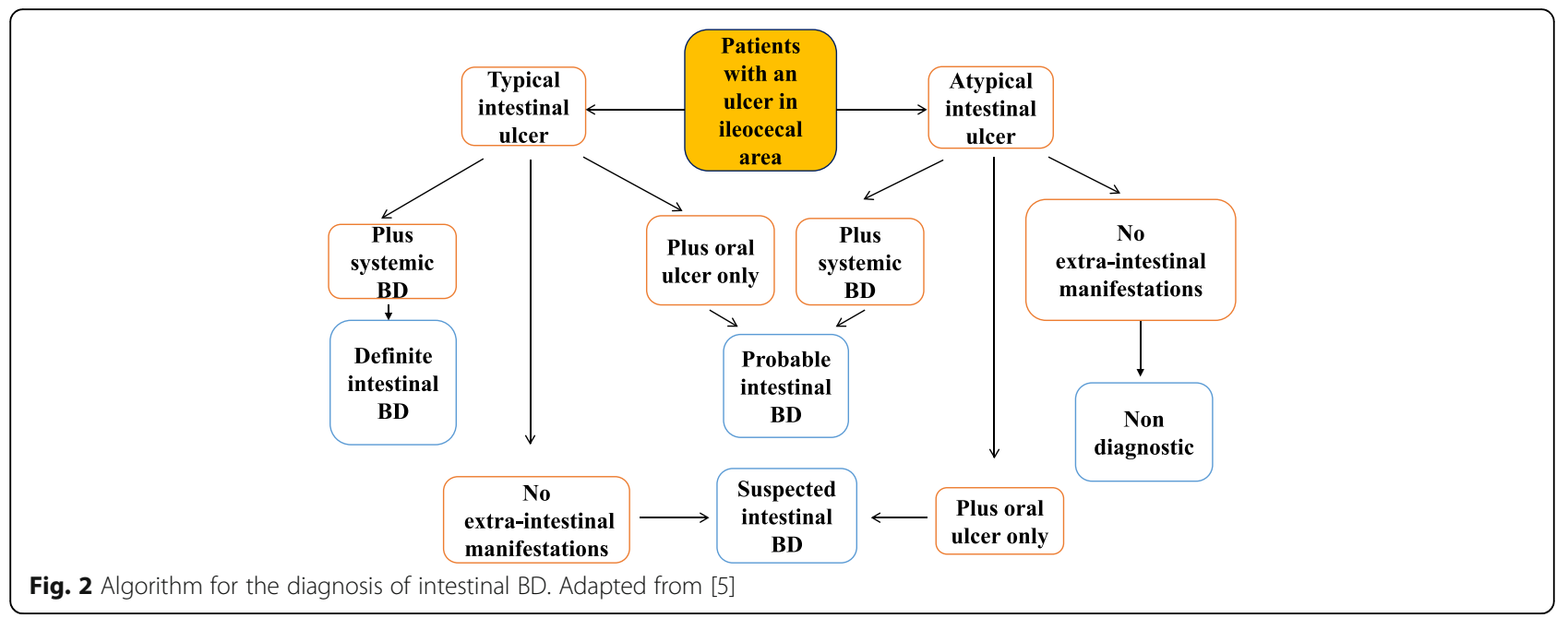

antigen recognized by anti-endothelial cell antibodies in the sera of patients with BD. IgM AAEAs were observed in 18 out of 40 patients with BD (45\%). Based on their results, they suggest that AAEA has the potential to be a diagnostic marker of BD [36]. Shin et al. assessed the prevalence of IgM AAEA in patients with intestinal BD and found that IgM AAEA can be helpful for the diagnosis of intestinal $\mathrm{BD}$, especially in patients without systemic manifestations of $\mathrm{BD}$. They evaluated the relationships between IgM AAEA and various intestinal BD-related clinical factors, suggesting the association between IgM AAEA and disease activity and severity [37]. Expression of ASCA reflects a specific mucosal immune-mediated response in $\mathrm{CD}$ [38]. ASCA frequency in CD patients ranges from 50 to $80 \%$ of total IgG and 30 to $50 \%$ of total IgA antibodies [39]. ASCA is found more often in CD (50$70 \%)$ than healthy controls $(<5 \%)$; these antibodies increase with age and are associated with a more severe disease course in CD [40]. The sensitivity and specificity of these antibodies in diagnosing Crohn's disease range from 40 to $70 \%$ and 82 to $89 \%$, respectively [41]. In conclusion, for both diseases, clinical diagnosis is not supported by specific serum markers.

\section{Endoscopic and histological features}

The most frequent localization of intestinal $\mathrm{BD}$, as in $\mathrm{CD}$, is the ileocecal area, although any part of the gastrointestinal tract, including oesophagus, stomach, duodenum, jejunum, colon and extra-intestinal organs, such as liver, pancreas, or spleen, can be affected. Diffuse colonic involvement is rare, but it occurs in approximately $15 \%$ of patients who have gastrointestinal involvement [15]. Skipped colonic lesions can be present both in BD and $\mathrm{CD}$ [42]. Endoscopic findings of intestinal $\mathrm{BD}$ are described as single or few, large, discrete, and round or oval shaped ulcerations in the ileocecal area [43]. However, these lesions vary from small aphthous ulcerations to multiple, irregular shaped ulcerations. In Crohn's disease, typical endoscopic findings include discontinuous distribution of longitudinal ulcers (defined as $\geq 4$ to $5 \mathrm{~cm}$ ), cobblestone appearance, and/or small aphthous ulcerations arranged in a longitudinal fashion. Lee et al., comparing colonoscopy findings of 115 intestinal BD and 135 CD patients, have proposed diagnostic criteria [44]. Round shape, fewer numbers $(\leq 5)$, focal distribution, discrete border, deep penetrating, ileocecal location and absence of aphthous and cobblestone appearance can be suggestive of typical ulcerations of intestinal BD (Fig. 4). There are no pathognomonic histologic findings regarding intestinal $\mathrm{BD}$. There are two forms of intestinal BD lesions: one is mucosal inflammation and ulceration (neutrophilic phlebitis), the other is ischemic damage (vasculitis) [9]. The most common features are: vasculitis affecting small veins and venules; and a normal circumferential mucosa surrounding a large ulceration. Absence of non-caseating granuloma suggests intestinal $\mathrm{BD}$ rather than $\mathrm{CD}$, even if non-caseating granulomas are observed in only $15-36 \%$ of patients with CD [13]. Histopathological characteristics of CD include discontinuous cryptic architectural abnormalities, discontinuous inflammation, focal cryptitis, and epithelioid granulomas [7] Table 1.

\section{Therapy}

Both $\mathrm{BD}$ and $\mathrm{CD}$ are multisystem, inflammatory conditions, and steroids with immunomodulatory agents are first-line therapies. The management of patients with BD is based on the presence of organ involvement and disease severity. Colchicine is widely used as first-line treatment for BD (muco-cutaneous and musculoskeletal findings). When colchicine is inadequate and ocular, vascular, neurological, or intestinal involvement is present, steroids and azathioprine can be indicated [7]. A small number of unresponsive patients may require mycophenolate mofetil or cyclophosphamide especially in cases of vascular and 


\begin{tabular}{|c|c|}
\hline CLINICAL FUNCTIONS & SCORE \\
\hline General well-being over the past week & 0 \\
\hline Well & 10 \\
\hline Fair & 20 \\
\hline Poor & 30 \\
\hline Very poor & 40 \\
\hline \multicolumn{2}{|l|}{ Terrible } \\
\hline Fever & 0 \\
\hline$<38^{\circ} \mathrm{C}$ & 10 \\
\hline \multicolumn{2}{|l|}{$\geq 38^{\circ} \mathrm{C}$} \\
\hline Extraintestinal manifestations & $\begin{array}{l}5 \text { per type of } \\
\text { manifestation* }\end{array}$ \\
\hline Abdominal pain over the past week & 0 \\
\hline None & 20 \\
\hline Mild & 40 \\
\hline Moderate & 80 \\
\hline \multicolumn{2}{|l|}{ Severe } \\
\hline Abdominal mass & 0 \\
\hline None & 10 \\
\hline \multicolumn{2}{|l|}{ Palpable mass } \\
\hline Abdominal tenderness & 0 \\
\hline None & 10 \\
\hline Middly tender & 20 \\
\hline \multicolumn{2}{|l|}{ Moderately or severely tender } \\
\hline Intestinal complications & $\begin{array}{l}10 \text { per type of } \\
\text { complication* }\end{array}$ \\
\hline Number of liquid stools over the past week & 0 \\
\hline 0 & 10 \\
\hline $1-7$ & 20 \\
\hline $8-21$ & 30 \\
\hline $22-35$ & 40 \\
\hline$\geq 36$ & \\
\hline
\end{tabular}

Fig. $3 * 5$ points are added for each type of the following manifestations: oral ulcers, genital ulcers, eye lesions, skin lesions, or arthralgia; 15 points are added for each of the following: vascular involvement or central nervous system involvement. ** Such as a fistula, perforation, abscess or intestinal obstruction. Adapted from [15]

neurological involvement [7]. No randomized prospective studies are present on the treatment of intestinal BD, which is very similar to $\mathrm{CD}$. There is controversy regarding the therapeutic effects of 5-amino-salicylates (5-ASA)/ sulfasalazine, which have routinely been employed in patients with IBD. 5-ASA should only be used to treat intestinal BD if clinical and endoscopic activity are mild [25]. Systemic corticosteroids (CSs) are often useful as first-line therapy either in the acute phase of intestinal BD or in patients with moderate to severe disease when treatment with 5-ASA/sulfasalazine fails. An initial dose of $0.5-1$ $\mathrm{mg} / \mathrm{kg}$ prednisolone and rapid tapering strategies are prevalent, similar to IBD treatment [13]. A retrospective cohort study in 54 patients with active intestinal BD treated with CSs therapy, showed complete remission in $46.3 \%$, partial remission in $42.6 \%$, and, in $11.1 \%$, no response after a month from treatment. After one year, $35.2 \%$ of patients showed corticosteroid dependency [45]. Although CSs are the main treatment for intestinal BD, many patients become CS-resistant or CS-dependent. Thiopurines or azathioprine/6-mercaptopurine (AZA/6MP) $(2.0-2.5 \mathrm{mg} / \mathrm{kg} /$ day $)$ are indicated in patients with steroid dependency or resistance. Jung et al., reported cumulative relapse rates of $5.8,28.7,43.7$, and $51.7 \%$ at 1,2 , 3 , and 5 years after remission among patients with intestinal BD who received AZA/6-MP [46]. Thalidomide (2 $\mathrm{mg} / \mathrm{kg} /$ day) has been demonstrated as capable of achieving symptom control and replacing steroid therapy in patients with intestinal BD [15]. Monoclonal antibodies to tumour necrosis factor- $\alpha$ (TNF- $\alpha$ ), including infliximab (IFX) and adalimumab (ADA), are biological agents for treating IBD, and are beneficial in patients who are unresponsive to conventional therapies. There are few randomized trials on the use of anti-TNF- $\alpha$ agents in patients with intestinal BD. The first patient with $\mathrm{BD}$ treated with infliximab was reported in 2001 [47]. A Korean retrospective multicenter study showed 28 cases of patients with intestinal BD refractory to conventional medical treatment and treated with IFX, with a clinical response rate of $64.8 \%$ at 4 weeks [48]. Maintenance infliximab treatment has shown to be more beneficial than shortterm treatment for maintaining remission in patients with intestinal BD [15]. Intestinal BD has also been successfully treated with adalimumab, a fully humanized IgG1 monoclonal antibody that binds to TNF- $\alpha$. The Japanese group in a consensus statement of anti-TNF- $\alpha$ therapy in patients with intestinal BD proposed its indication as a standard therapy for intestinal BD [49]. Recently, adalimumab has successfully been used as a first-line anti-TNF- $\alpha$ agent in patients with steroid-dependent intestinal BD to induce and maintain complete remission [50]. Although there is proven efficacy of anti-TNF- $\alpha$ agents in intestinal $\mathrm{BD}$, further randomized, prospective trials are necessary to confirm these findings. Cantarini et al. [51] has reported efficacy of a novel class of therapies directed against specific cytokines implicated in the disease, as Anakinra. It is an interleukin-1 receptor antagonist with effectiveness in BD with bowel involvement amd resistant 


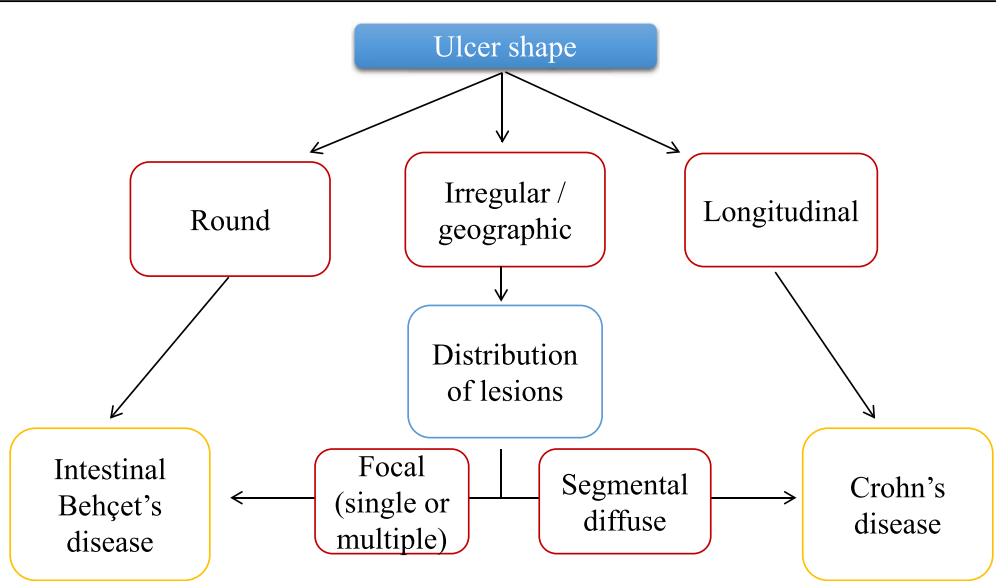

Fig. 4 Endoscopic lesions differentiating between intestinal Behçet Disease and Crohn's Disease. Adapted from [44]

to others immunomodulatory agents (anti-TNF- $\alpha$ ). Management options for CD include nutritional therapy, drug therapy, and, in severe or chronic active disease, surgery. The aims of $\mathrm{CD}$ treatment are to reduce symptoms and maintain or improve quality of life. Steroids are the first-line therapy for CD. The European Crohn's and Colitis Organization (ECCO) recommend budesonide 9 mg daily to induce remission in mildly active, localized ileocecal CD with $50-60 \%$ remission at 8 weeks of therapy [52]. Although it is less efficacious to conventional steroids, especially in the case of severe disease, it has fewer side effects. Moya et al., in a detailed meta-analysis, showed that mesalazine (4 g/day) has a very marginal benefit confirming that budesonide is the best option in mild disease, and found no clear evidence for mesalazine being better than placebo at any dose [53]. Exclusive enteral nutrition therapy is regarded as appropriate only for adjunctive treatment to support nutrition and not for primary therapy, while it is recommended as first line therapy to induce remission in children with active luminal CD [52]. According to ECCO guidelines, moderately active localized ileocaecal CD should be treated with budesonide, or systemic corticosteroids [52]. In the case of steroid-refractory or intolerance, an anti-TNF $\alpha$ based strategy should be used both in adult and pediatric population [54]. In conclusion, medical and surgical therapies are similar in BD and CD but the biological therapy seems to be more efficacious in $\mathrm{CD}$ than $\mathrm{BD}$.

\section{Surgery}

When patients with intestinal BD are refractory to medical treatment or present serious complications, such as bowel perforation, severe bleeding, fistulae, obstructions, or abdominal masses, surgical treatment is required. Although

Table 1 Crohn's disease and Behçet's disease: clinical features

\begin{tabular}{|c|c|c|}
\hline & Crohn's disease & Behcet's disease \\
\hline Clinical manifestations & $\begin{array}{l}\text { Abdominal pain, diarrhoea, rectal bleeding, } \\
\text { nausea, vomiting, weight loss and fever }\end{array}$ & $\begin{array}{l}\text { Oral and genital ulcers, joints and neurological } \\
\text { involvement }\end{array}$ \\
\hline Extra intestinal manifestations & $\begin{array}{l}\text { Uveitis, arthritis, pyoderma gangrenosum, } \\
\text { erythema nodosum, iron deficiency } \\
\text { anaemia }\end{array}$ & $\begin{array}{l}\text { Uveitis, arthritis, pyoderma gangrenosum, } \\
\text { erythema nodosum, vaso-occlusive disease } \\
\text { and thrombotic events }\end{array}$ \\
\hline Histological features & $\begin{array}{l}\text { Discontinuous distribution of longitudinal } \\
\text { ulcers, aphthous and cobblestone } \\
\text { appearance, focal cryptitis and epithelioid } \\
\text { granulomas }\end{array}$ & $\begin{array}{l}\text { Mucosal inflammation and ulceration; } \\
\text { signs of vasculitis. }\end{array}$ \\
\hline Most involved gender & Female & Male \\
\hline Genetic predominant factor & $\begin{array}{l}\text { NOD2/CARD15 (16p12-q13), CXCL16 (17p13), } \\
\text { STAT6 (12q13), TLR4 (9q33), CARD9 (9q34.3) }\end{array}$ & HLA-B51 \\
\hline Therapy & $\begin{array}{l}\text { Systemic corticosteroids 5-ASA/sulfasalazine } \\
\text { Thiopurines or AZA/6-MP Anti TNF-a agents } \\
\text { Nutritional therapy }\end{array}$ & $\begin{array}{l}\text { Colchicine Systemic corticosteroids Mycophenolate } \\
\text { mofetil Cyclophosphamide Thiopurines or } \\
\text { AZA/6-MP Anti TNF-a agents }\end{array}$ \\
\hline Surgery & $\begin{array}{l}\text { Patients refractory to medical treatment or } \\
\text { with complications }\end{array}$ & $\begin{array}{l}\text { Refractory to medical treatment or with complications } \\
\text { such as perforations, fistulae formation, and massive } \\
\text { gastrointestinal bleeding }\end{array}$ \\
\hline
\end{tabular}


remission rates with medical therapy are similar to those reported in $\mathrm{CD}$, in intestinal $\mathrm{BD}$, surgical intervention is more frequent [55]. Intestinal BD requires surgical intervention due to complications such as perforations, fistulae formation, and massive gastrointestinal bleeding, which occur in up to $50 \%$ of patients [56]. Park et al. showed that cumulative rates of surgical interventions in intestinal BD are $20 \%$ at 1 year, $27-33 \%$ at 5 years and $31-46 \%$ at 10 years after diagnosis [45]. Many clinical variables have been investigated as predictors of outcomes during medical and surgical therapy: young age, high disease activity at time of diagnosis, "volcano-type" ulcers on endoscopy or colonoscopy, elevated CRP and history of laparotomy confer the poorest prognosis [57]. Surgery is a reasonable alternative for patients with $\mathrm{CD}$ refractory to conventional medical treatment and should also be discussed. Surgery is the preferred option in patients with localised ileocecal $\mathrm{CD}$, which requires surgery in $90 \%$ of patients with obstructive symptoms [54]. Surgery in CD is not curative: post-operative recurrence rate is lowest when measured by repeat resection, intermediate when clinical indices are used and highest when endoscopy is employed as the diagnostic tool. In population-based studies, the clinical post-operative recurrence rate ranged from 28 to $45 \%$ and from 36 to $61 \%$ at 5 and 10 years, respectively. It has been demonstrated that the post-operative clinical course of $\mathrm{CD}$ is best predicted by the severity of endoscopic lesions [54]. One study compared long-term clinical outcomes between intestinal $\mathrm{BD}$ and $\mathrm{CD}$. The probabilities of surgery, hospital admission, and post-operative recurrence were not significantly different between intestinal BD and CD $(44.4 \%$ vs. $36.0 \%, 69.2 \%$ vs. $73.8 \%$, and $66.5 \%$ vs. $79.1 \%$ at 10 years, $p=0.287,0.295$, and 0.724 , respectively), but the rates of corticosteroid and immunosuppressant use were higher in intestinal BD than in Crohn's disease $(59.4 \%$ vs. $42.6 \%$ and $37.7 \%$ vs. $27.1 \%, p<0.001$ and $<0.001$, respectively) [58].

\section{Conclusions}

Intestinal $\mathrm{BD}$ and $\mathrm{CD}$ are inflammatory diseases with similar multisystem involvement and various extra-intestinal signs and symptoms. Intestinal BD shares clinical courses, endoscopic and histologic features with IBD, particularly $\mathrm{CD}$. It may be extremely difficult to distinguish intestinal BD from IBD due to similarities in intestinal and extraintestinal manifestations, and pathologic findings. Differential diagnosis between intestinal $\mathrm{BD}$ and $\mathrm{CD}$ remains a challenge for clinicians, and both conditions have significant clinical, diagnostic and therapeutic overlaps.

\section{Abbreviations}

5-ASA: 5-amino-salicylates; AAEA: Antia-enolase antibody; ADA: Adalimumab; ASCA: Anti-Saccharomyces cerevisiae antibodies; AZA/6-MP: Azathioprine/6mercaptopurine; BD: Behçet disease; CD: Crohn's disease; CDAl: Crohn's disease activity index; CSs: Systemic corticosteroids; DAIBD: Disease activity index for intestinal Behçet's disease; IBD: Inflammatory bowel disease; IFX: Infliximab; IL: Interleukin; ISG: International study group; TNF-a: Tumour necrosis factor-a

\section{Acknowledgements}

Not applicable.

\section{Funding}

This review did not receive funding. The authors have no financial relationships to disclose that are relevant for this article.

\section{Availability of data and materials}

Data sharing not applicable to this article as no datasets were generated or analyzed during the current study.

\section{Authors' contributions}

SV and CR conceptualized the initial manuscript. SV drafted the manuscript. $R G, D D V$ and $C R$ have reviewed and edited the manuscript. All authors read and approved the final version.

\section{Competing interests}

The authors declare that they have no competing interests.

Consent for publication

Not applicable.

Ethics approval and consent to participate

Not applicable.

\section{Publisher's Note}

Springer Nature remains neutral with regard to jurisdictional claims in published maps and institutional affiliations.

Received: 31 January 2017 Accepted: 11 April 2017

Published online: 20 April 2017

\section{References}

1. Baumgart DC, Sandborn WJ. Crohn's disease. Lancet. 2012;380:1590-605. doi:10.1016/S0140-6736(12)60026-9. PMID: 22914295.

2. Behçet $H$. Rezidivierende aphthose, durch ein virus verusachte geschwure am auge und an den genitalien. Dermatol Wochenschr. 1937;105:1152-7.

3. Ciccarelli F, De Martinis M, Ginaldi L. An update on autoinflammatory diseases. Curr Med Chem. 2014;21(3):261-9.

4. Sakane T, Takeno M, Suzuki N, et al. Behçet's disease. N Engl J Med. 1999;341:1284-91.

5. Cheon JH, Kim ES, Shin SJ, et al. Development and validation of novel diagnostic criteria for intestinal Behçet's disease in Korean patients with ileocolonic ulcers. Am J Gastroenterol. 2009;104:2492-9.

6. Hatemi I, Esatoglu SN, Hatemi G, et al. Characteristics, treatment, and long-term outcome of gastrointestinal involvement in Behcet's syndrome: a strobe-compliant observational study from a dedicated multidisciplinary center. Medicine (Baltimore). 2016;95(16):e3348. doi:10.1097/MD.0000000000003348.

7. Bayraktar Y, Ozaslan E, Van Thiel DH. Gastrointestinal manifestations of Behcet's disease. J Clin Gastroenterol. 2000;30:144-54.

8. Hung $\mathrm{CH}$, Lee JH, Chen ST, et al. Young children with Behçet disease have more intestinal involvement. J Pediatr Gastroenterol Nutr. 2013;57:225-9. doi:10.1097/MPG.0b013e3182936ec4. PMID: 23880628.

9. Ananthakrishnan AN. Epidemiology and risk factors for IBD. Nat Rev Gastroenterol Hepatol. 2015;12(4):205-17. doi:10.1038/nrgastro.2015.34. Epub 2015 Mar 3 .

10. Koné-Paut I. Behçet's disease in children, an overview. Pediatr Rheumatol Online J. 2016;14(1):10. doi:10.1186/s12969-016-0070-z.

11. Yazısız V. Similarities and differences between Behçet's disease and Crohn's disease. World J Gastrointest Pathophysiol. 2014;5(3):228-38. doi:10.4291/ wjgp.v5.i3.228.

12. Mazzoccoli G, Matarangolo A, Rubino R, et al. Behçet syndrome: from pathogenesis to novel therapies. Clin Exp Med. 2016;16(1):1-12. doi:10. 1007/s10238-014-0328-z. Epub 2014 Dec 2. 
13. Kim DH, Cheon JH. Intestinal Behçet's disease: a true inflammatory bowel disease or merely an intestinal complication of systemic vasculitis? Yonsei Med J. 2016;57(1):22-32.

14. Direskeneli $\mathrm{H}$. Behçet's disease: infectious aetiology, new autoantigens, and HLA-B51. Ann Rheum Dis. 2001;60:996-1002

15. Grigg EL, Kane S, Katz S. Mimicry and deception in inflammatory bowel disease and intestinal behçet disease. Gastroenterol Hepatol (N Y). 2012;8(2):103-12.

16. Parkes M. The genetics universe of Crohn's disease and ulcerative colitis. Dig Dis. 2012;30 Suppl 1:78-81. doi:10.1159/000341130. PMID: 23075873.

17. Mizuki N, Meguro A, Ota M, et al. Genome-wide association studies identify IL23R-IL12RB2 and IL10 as Behçet's disease susceptibility loci. Nat Genet. 2010:42:703-6.

18. Remmers EF, Cosan F, Kirino Y, et al. Genome-wide association study identifies variants in the MHC class I, IL10, and IL23R-IL12RB2 regions associated with Behçet's disease. Nat Genet. 2010;42:698-702.

19. Franke A, McGovern DP, Barrett JC, et al. Genome-wide meta-analysis increases to 71 the number of confirmed Crohn's disease susceptibility loci. Nat Genet. 2010;42:1118-25.

20. Cho JH, Brant SR. Recent insights into the genetics of inflammatory bowel disease. Gastroenterology. 2011;140:1704-12.

21. Park UC1, Kim TW2, Yu HG. Immunopathogenesis of ocular Behçet's disease. J Immunol Res. 2014:2014:653539. doi:10.1155/2014/653539. Epub 2014 Jul.

22. Zeidan MJ, Saadoun D, Garrido M, et al. Behcet's disease physiopathology: a contemporary review Autoimmun Highlights. 2016;7: 4. doi 10.1007/s13317-016-0074-1

23. Harbord M, Annese V, Vavricka SR, et al. The first european evidence-based consensus on extra-intestinal manifestations in inflammatory bowel disease. J Crohns Colitis. 2016;10(3):239-54. doi:10.1093/ecco-jcc/jjv213. Epub 2015 Nov 27.

24. Fatemi A, Shahram F, Akhlaghi M, et al. Prospective study of articular manifestations in Behcet's disease: five-year report. Int J Rheum Dis. 2015;25 doi: 10.1111/1756-185X.12633.

25. Cheon JH, Celik AF, Kim WH. Behçet's disease: gastrointestinal involvement In: Yazici Y, Yazici H, editors. Behçet's Syndrome. 1st ed. New York: Springer; 2010. p. 165-88.

26. Griffiths AM. Specificities of inflammatory bowel disease in childhood. Best Pract Res Clin Gastroenterol. 2004;18:509-23.

27. Van Limbergen J, Russell RK, Drummond HE, et al. Definition of phenotypic characteristics of childhood-onset inflammatory bowel disease. Gastroenterology. 2008;135:1114-22.

28. Vavricka SR, Spigaglia SM, Rogler G, et al. Systematic evaluation of risk factors for diagnostic delay in inflammatory bowel disease. Inflamm Bowel Dis. 2012;18:496-505.

29. Lemberg DA, Day AS. Crohn disease and ulcerative colitis in children: an update for 2014. J Paediatr Child Health. 2015;51(3):266-70. doi:10.1111/jpc. 12685. Epub 2014 Jul 15.

30. International Study Group for Behçet's Disease. Criteria for diagnosis of Behçet's disease. Lancet. 1990;335:1078-80.

31. Koné-Paut I, Shahram F, Darce-Bello $M$, et al. Consensus classification criteria for paediatric Behçet's disease from a prospective observational cohort: PEDBD. Ann Rheum Dis. 2016;75(6):958-64. doi:10.1136/ annrheumdis-2015-208491. Epub 2015 Dec 23.

32. Best WR, Becktel JM, Singleton JW, et al. Development of a Crohn's disease activity index. Gastroenterology. 1976;70:439-44.

33. Cheon JH, Han DS, Park JY, Korean IBD Study Group, et al. Development, validation, and responsiveness of a novel disease activity index for intestinal Behçet's disease. Inflamm Bowel Dis. 2011;17:605-13.

34. Lee HJ, Kim YN, Jang HW, et al. Correlations between endoscopic and clinical disease activity indices in intestinal Behcet's disease. World J Gastroenterol. 2012;18:5771-8.

35. Choi $\mathrm{CH}$, Kim Tl, Kim BC, et al. Anti-Saccharomyces cerevisiae antibody in intestinal Behçet's disease patients: relation to clinical course. Dis Colon Rectum. 2006;49:1849-59.

36. Shin SJ, Kim BC, Kim Tl, et al. Anti-alpha-enolase antibody as a serologic marker and its correlation with disease severity in intestinal Behçet's disease. Dig Dis Sci. 2011;56:812-8.

37. Lee $\mathrm{KH}$, Chung HS, Kim HS, et al. Human alpha-enolase from endothelial cells as a target antigen of anti-endothelial cell antibody in Behçet's disease. Arthritis Rheum. 2003;48:2025-35.

38. Main J, McKenzie H, Yeaman GR, et al. Antibody to Saccharomyces cerevisiae (bakers' yeast) in Crohn's disease. Br Med J. 1988;297:1105-6.
39. Ruemmele FM, Targan SR, Levy G, et al. Diagnostic accuracy of serological assays in pediatric inflammatory bowel disease. Gastroenterology. 1998;115:822-9.

40. Levine A, Koletzko S, Turner D. ESPGHAN revised porto criteria for the diagnosis of inflammatory bowel disease in children and adolescents. J Pediatr Gastroenterol Nutr. 2014;58(6):795-806. doi:10.1097/MPG. 0000000000000239

41. Peeters $M$, Joossens $S$, Vermeire $S$, et al. Diagnostic value of anti-Saccharomyces cerevisiae and anti-neutrophil cytoplasmic autoantibodies in inflammatory bowel disease. Am J Gastroenterol. 2001;96:730-4.

42. Kim DH, Chan HC, Lung PFC, et al. Ileocolonoscopy in Crohn's disease. In: Kim WH, Cheon JH, editor. Atlas of inflammatory bowel diseases. 1st ed. New York: Springer Berlin Heidelberg; 2015. p. 31-51.

43. Lee CR, Kim WH, Cho YS, et al. Colonoscopic findings in intestinal Behçet's disease. Inflamm Bowel Dis. 2001;7:243-9.

44. Lee SK, Kim BK, Kim TI, et al. Differential diagnosis of intestinal Behçet's disease and Crohn's disease by colonoscopic findings. Endoscopy. 2009:41:9-16.

45. Park JJ, Kim WH, Cheon JH. Outcome predictors for intestinal Behçet's disease. Yonsei Med J. 2013;54:1084-90.

46. Jung YS, Cheon JH, Hong SP, et al. Clinical outcomes and prognostic factors for thiopurine maintenance therapy in patients with intestinal Behcet's disease. Inflamm Bowel Dis. 2012:18:750-7.

47. Hassard PV, Binder SW, Nelson V, et al. Anti-tumor necrosis factor monoclonal antibody therapy for gastrointestinal Behçet's disease: a case report. Gastroenterology. 2001;120:995-9.

48. Lee JH, Cheon JH, Jeon SW, et al. Efficacy of infliximab in intestinal Behçet's disease: a Korean multicentre retrospective study. Inflamm Bowel Dis. 2013;19:1833-8.

49. Hisamatsu T, Ueno F, Matsumoto T, et al. The 2nd edition of consensus statements for the diagnosis and management of intestinal Behçet's disease: indication of anti-TNFa monoclonal antibodies. J Gastroenterol. 2014;49:156-62.

50. De Cassan C, De Vroey B, Dussault C, et al. Successful treatment with adalimumab in a familial case of gastrointestinal Behçet's disease. J Crohns Colitis. 2011:5:364-8.

51. Vitale A, Rigante D, Lopalco G, et al. Interleukin-1 Inhibition in Behçet's disease. Isr Med Assoc J. 2016:18(3-4):171-6.

52. Ruemmele FM, Veres $\mathrm{G}$, Kolho $\mathrm{KL}$, et al. Consensus guidelines of ECCO/ ESPGHAN on the medical management of pediatric Crohn's disease. doi: http://dx.doi.org/10.1016/j.crohns.2014.04.005 1179-1207 First published online: 1 October 2014.

53. Moja L, Danese S, Fiorino G, et al. Systematic review with network meta-analysis: comparative efficacy and safety of budesonide and mesalazine (mesalamine) for Crohn's disease. Aliment Pharmacol Ther 2015;41(11):1055-65. doi:10.1111/apt.13190. Epub 2015 Apr 13.

54. Gomollón F, Dignass A, Annese V et al., 3rd European Evidence-based Consensus on the Diagnosis and Management of Crohn's Disease 2016: Part 1: Diagnosis and Medical Management. J Crohns Colitis. 2016:1-23. doi:10. 1093/ecco-jcc/jjw168 Ecco Guideline/Consensus Paper.

55. Jung YS, Cheon JH, Park SJ, et al. Longterm clinical outcomes of Crohn's disease and intestinal Behcet's disease. Inflamm Bowel Dis. 2013;19:99-105.

56. Moon CM, Cheon JH, Shin JK, et al. Prediction of free bowel perforation in patients with intestinal Behçet's disease using clinical and colonoscopic findings. Dig Dis Sci. 2010;55:2904-11.

57. Skef W, Hamilton MJ, Arayssi T. Gastrointestinal Behçet's disease: a review. World J Gastroenterol. 2015;21(13):3801-12. doi:10.3748/wjg.v21.i13.3801

58. Jung YS, Yoon JY, Lee JH, et al. Prognostic factors and long-term clinical outcomes for surgical patients with intestinal Behcet's disease. Inflamm Bowel Dis. 2011;17:1594-602. 